\title{
Knowledge about obstetric danger signs among pregnant women attending antenatal clinic in a tertiary care hospital of Delhi: a cross sectional study
}

\author{
Ashok Kumar ${ }^{1 *}$, Geeta Yadav $^{1}$, Vijay Zutshi ${ }^{2}$, Suman Bodat ${ }^{3}$
}

\author{
${ }^{1}$ Department of Community Medicine, VMMC and Safdarjung Hospital, New Delhi, India \\ ${ }^{2}$ Department of Obstetrics and Gynecology, VMMC and Safdarjung Hospital, New Delhi, India \\ ${ }^{3}$ Department of Community Medicine, GMC Pali, Rajasthan, India
}

Received: 04 July 2019

Accepted: 08 August 2019

\section{*Correspondence:}

Dr. Ashok Kumar,

E-mail: akjakhar16@gmail.com

Copyright: ( $)$ the author(s), publisher and licensee Medip Academy. This is an open-access article distributed under the terms of the Creative Commons Attribution Non-Commercial License, which permits unrestricted non-commercial use, distribution, and reproduction in any medium, provided the original work is properly cited.

\section{ABSTRACT}

Background: According to UNICEF, globally 800 million women die due to preventable causes related to pregnancy and childbirth; $20 \%$ of which occur in India. It is therefore imperative to understand the level of knowledge about danger signs among pregnant women to augment timely redressal of preventive obstetric causes of mortality.

Methods: A hospital based, cross sectional study was conducted at the ANC Clinic in Safdarjung Hospital, New Delhi from $2^{\text {nd }}$ July to $27^{\text {th }}$ July 2018 . Convenient sampling was used to identify and interview 354 pregnant women, using a semi structured questionnaire. Data was entered and analysed with SPSSv21. Results were presented as frequencies and proportions. Chi square was used to test for association between qualitative variables, and p-value less than 0.05 was considered significant.

Results: $48.3 \%, 35.6 \%$, and $40.1 \%$ of pregnant women had knowledge about danger signs during pregnancy, labour and postpartum respectively. Majority of the women had knowledge about abdominal pain (58.4\%) and severe fatigue $(80.7 \%)$ as danger signs of pregnancy, while bleeding $(82.5 \%)$ was the most common response as danger sign of labour. More than half had knowledge about heavy bleeding $(59.9 \%)$ as danger sign of postpartum. The women lacked awareness about Convulsions (92.9\%) as danger signs of pregnancy and labour, as well as smelly vaginal discharge $(79.6 \%)$ in postpartum.

Conclusions: Knowledge of obstetric danger signs among pregnant women is still lower. It needs further awareness as it can help in early diagnosis and referral of patients thus reducing maternal mortality and morbidity.

Keywords: Awareness, Danger sign, Labour, Maternal mortality, Postpartum, Pregnancy

\section{INTRODUCTION}

Maternal mortality, as defined by WHO, refers to "deaths of women while pregnant or within 42 days of termination of pregnancy, irrespective of duration and site of pregnancy from any cause related to or aggravated by the pregnancy or its management but not from accidental or incidental causes". ${ }^{1}$
According to UNICEF, globally 800 million women die due to preventable causes related to pregnancy and childbirth; $20 \%$ of which occur in India. It was reported that in India around 44,000 women die due to pregnancy and childbirth related complications. ${ }^{2}$ The high number of maternal deaths in some areas of the world reflects inequities in access to health services, rampant illiteracy, ignorance and gender inequality. The risk of maternal 
mortality is highest for adolescent girls under 15 years of age. $^{3}$

According to WHO, hemorrhage is the leading cause of maternal mortality worldwide (3), hypertensive disorders associated with pregnancy namely eclampsia, embolism also claim significant number of lives. In South East Asia the lifetime risk of maternal death is 1 in 200 among the pregnant females. ${ }^{3}$

Danger signs during pregnancy encompass all the conditions during pregnancy which can endanger the life of the fetus and the mother. Educational status, occupation and the number of ANC visits are some of the major factors affecting the level of knowledge about danger signs among the pregnant women.

Most maternal deaths are in resource poor countries. "Delay to make a decision to seek care, delay to reach place of care and delay in receiving appropriate and adequate care" are the main attributed to the three delays. $^{4}$

Recognizing maternal mortality as a major indicator of health of a nation, studies were conducted in Indian hospitals as well to gauge the status of maternal health in India. India being a fairly diverse country also has wide disparities in the results of these studies. Studies show that the incidence of maternal mortality decreases significantly with education. With widespread use of education, information and communication, many more women are now aware about the pregnancy related complications during the antenatal period, however there appears a lag in the awareness regarding the complications during labor and the post-natal period.

The knowledge about obstetric danger signs and its relation with complications during pregnancy labor and post-partum period would helps pregnant women and their families in seeking timely health care services when required and thus can decrease the maternal mortality.

Women should be made aware of danger signs of obstetric complications during pregnancy, delivery and the postpartum. ${ }^{5}$ For the enhancing the utilization of skilled care during low-risk births and emergency obstetric care in complicated cases in low income countries, knowledge of obstetric danger signs and birth preparedness are the major strategies. ${ }^{6,7}$ Maternal deaths due to obstetric complications can be reduced with the presence of skilled attendants at births and availability of emergency obstetric care. ${ }^{8-10}$ And this depends on a functional referral system from rural communities to health facilities. ${ }^{11}$

Knowledge regarding danger signs will help a pregnant woman to take appropriate action needed. Thus, this study was conducted to assess knowledge of obstetric danger signs among women attending Antenatal Clinic in a tertiary care hospital of Delhi.

\section{METHODS}

A hospital based descriptive cross sectional study was conducted in the month of July 2018 at Ante-natal clinic in Safdarjung hospital, New Delhi. Safdarjung hospital is a tertiary care hospital in Delhi which caters to population from Delhi as well as adjoining states.

The present study was conducted among pregnant women attending antenatal clinic. The minimum sample size came out to be 354 using the formula $4 \mathrm{pq} / 12$ and taking non response rate of $10 \%$. For this prevalence was taken as $28 \% \mathrm{q}$ (Sahithi $\mathrm{K}$ et al) as 72 , absolute error as $5 \%$ at $95 \%$ confidence interval. ${ }^{12}$

The study was conducted by convenient sampling technique until required sample size was attained. As on an average around 300 pregnant women attend Antenatal Clinic every $3^{\text {rd }}$ women visiting ANC was selected for the study. This procedure was repeated till the required sample size was achieved. Pregnant women who were having complications or seriously ill and had relatives in the hospital were excluded.

A semi structured, pretested, semi open-ended, interviewer administered, bilingual questionnaire was used to collect information regarding socio-demographic profile like age, sex, marital status, education, occupation etc., obstetric history and knowledge of danger obstetric signs during antenatal period, labour and post-partum.

\section{Statistical analysis}

Statistical analysis was done using a licensed version of SPSS 21. Descriptive analysis was done by calculating proportions, means and standard deviation. Chi square/Fishers Exact test for qualitative and test for quantitative variable were applied. The ethical clearance was obtained from Institutional Ethics Committee.

\section{RESULTS}

A total of 354 pregnant women attending ANC at Vardhman Mahavir Medical College and Safdarjung Hospital were studied.

\section{Sociodemographic profile}

Age of the study participants was normally distributed. Mean age was 25.76 years with standard deviation (SD) of 3.27 years. Minimum age was 18 years and the oldest participant was 33 years old. Maximum participants, 154 (43.5\%) belonged to the age group of 25 to 28 years, followed by $89(25.1 \%)$ in the age group of 21 to 24 years. Most of participants $308(87 \%)$ belonged to Hindu religion. $271(76.6 \%)$ participants were from urban area. Most of participants educated up to primary school i.e. $122(34.5 \%)$ followed by secondary school i.e. 116 (32.8\%). $127(35.9 \%)$ participants were from class III (middle) followed by Class VI (Lower middle) 
socioeconomic status i.e. $122(34.5 \%)$. Most of participants belonged to Joint family i.e. 193 (54.5\%) (Table 1).

Table 1: Sociodemographic profile of study participants $(\mathrm{N}=354)$.

\begin{tabular}{|lll|}
\hline Age group & Numbers & Percent \\
\hline Up to 20 years & 26 & 7.3 \\
\hline 21-24 years & 89 & 25.1 \\
\hline 25-28 years & 154 & 43.5 \\
\hline 29-33 years & 85 & 24 \\
\hline Religion & & \\
\hline Hindu & 308 & 87 \\
\hline Muslim & 34 & 9.6 \\
\hline Christian & 6 & 1.7 \\
\hline Others & 6 & 1.7 \\
\hline Total & 354 & 100 \\
\hline Education & & \\
\hline Illiterate & 7 & 2 \\
\hline Up to primary school & 53 & 15 \\
\hline Up to upper primary & 122 & 34.5 \\
\hline Up to secondary & 116 & 32.8 \\
\hline Up to higher secondary & 48 & 13.6 \\
\hline Graduate and above & 8 & 2.3 \\
\hline $\begin{array}{l}\text { Socioeconomic status: (Modified BG Prasad scale } \\
\text { 2018) (Based on income in Rs. } \\
\text { month) }\end{array}$ & & \\
\hline Class I (Upper) & 22 & 6.2 \\
\hline Class II (Upper middle) & 65 & 18.5 \\
\hline Class III (Middle) & 127 & 35.9 \\
\hline Class IV (Lower middle) & 122 & 34.5 \\
\hline Class V (Lower) & 18 & 5.1 \\
\hline Type of family & 161 & 45.5 \\
\hline Nuclear & 193 & 54.5 \\
\hline Joint & & \\
\hline & & \\
\hline & & \\
\hline & & \\
\hline
\end{tabular}

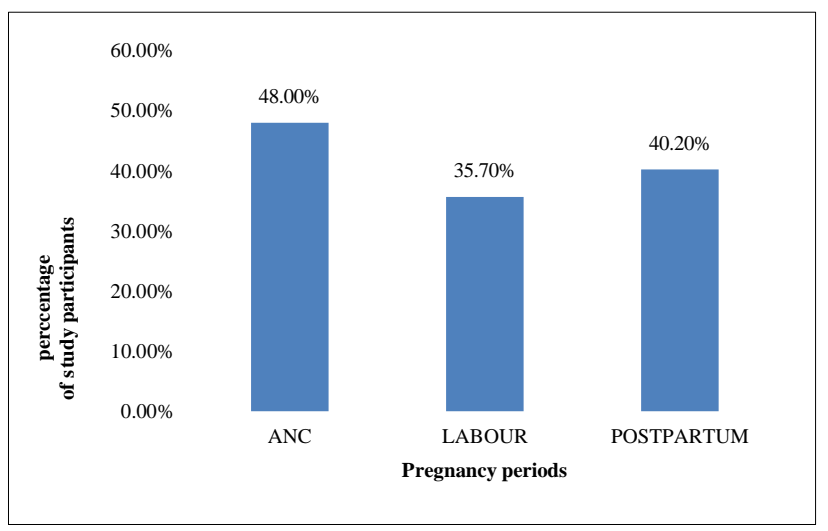

Figure 1: Knowledge of obstetric danger sign.

\section{Knowledge of danger signs during pregnancy, labour and postpartum period}

Out of 354 women, 170 (48\%), $126(35.6 \%)$ and 142 $(40.2 \%)$ had the knowledge of atleast one danger sign during the antenatal period, during labour and during post-partum period respectively (Figure 1).

Table 2: Knowledge of danger signs during antenatal period among study participants $(n=170)$.

\begin{tabular}{|ll|}
\hline Danger sign & $\mathrm{n}(\%)$ \\
\hline Abdominal pain & $147(85.9 \%)$ \\
\hline Severe fatigue & $141(82.4 \%)$ \\
\hline Vaginal bleeding & $112(65.9 \%)$ \\
\hline Fever & $94(55 \%)$ \\
\hline Difficulty breathing & $66(38.5 \%)$ \\
\hline Headache & $65(38.0 \%)$ \\
\hline Blurred vision & $67(38 \%)$ \\
\hline Swelling/Edema & $39(22.8 \%)$ \\
\hline Foul smelling vaginal discharge & $25(14.6 \%)$ \\
\hline Unconsciousness & $16(9.3 \%)$ \\
\hline Convulsions & $10(5.8 \%)$ \\
\hline *multiple response & \\
\hline
\end{tabular}

Out of 170 study participants, most of i.e. $147(85.7 \%)$ participants had knowledge about abdominal pain followed by severe fatigue i.e. $141(82.4 \%)$ as a danger sign during antenatal period while only $10 \quad(5.8 \%)$ participants had the knowledge about convulsion as a danger sign during this period (Table 2).

Table 3: Knowledge of danger signs during labour among study participants $(n=126)$.

\begin{tabular}{|ll|}
\hline Danger sign & n $(\%)$ \\
\hline Heavy bleeding & $105(83.3 \%)$ \\
\hline Vaginal tearing & $72(57.1 \%)$ \\
\hline Water break, labour not induced & $60(47.6 \%)$ \\
\hline Green/brown vaginal discharge & $47(37.3 \%)$ \\
\hline Retained placenta & $46(36.5 \%)$ \\
\hline Prolonged labour & $34(26.9 \%)$ \\
\hline Fever & $22(17.5 \%)$ \\
\hline Convulsions & $6(4.8 \%)$ \\
\hline *multiple responses &
\end{tabular}

Table 4: Knowledge of danger signs during postpartum period among study participants $(n=142)$.

\begin{tabular}{|ll|}
\hline Danger sign & n (\%) \\
\hline Heavy bleeding & $92(64.8 \%)$ \\
\hline Painful urination & $59(41.5 \%)$ \\
\hline High fever & $58(40.8 \%)$ \\
\hline Hot, swollen, painful breasts 48 33.8\% & $48(33.8 \%)$ \\
\hline Smelly vaginal discharge & $33(23.2 \%)$ \\
\hline *multiple responses & \\
\hline
\end{tabular}

Out of 126 study participants, most of i.e. 105 (83.3\%) participants had knowledge about heavy bleeding followed by vaginal tearing i.e. $72(57.1 \%)$ as a danger sign during labour while only $6(4.8 \%)$ participants had the knowledge about convulsion as a danger sign during this period (Table 3 ). 
Table 5: Association of knowledge of obstetric danger signs and age among study participants.

\begin{tabular}{|c|c|c|c|c|c|c|c|c|c|}
\hline \multirow[b]{2}{*}{$\begin{array}{l}\text { Age } \\
\text { (years) }\end{array}$} & \multicolumn{3}{|c|}{ Antepartum } & \multicolumn{3}{|l|}{ Labour } & \multicolumn{3}{|c|}{ Post partum } \\
\hline & Yes & No & $\begin{array}{l}P \text { - } \\
\text { value }\end{array}$ & Yes & No & P-value & Yes & No & alue \\
\hline $\begin{array}{l}<20(\mathrm{n}- \\
26)\end{array}$ & $11(42.3 \%)$ & $15(57.7 \%)$ & \multirow{4}{*}{0.211} & $5(19.2 \%)$ & $21(80.8 \%)$ & \multirow{4}{*}{0.115} & $9(34.6 \%)$ & $17(65.4 \%)$ & \multirow{4}{*}{0.829} \\
\hline $\begin{array}{l}21-24 \\
(n-89)\end{array}$ & $39(43.8 \%)$ & $50(56.2 \%)$ & & $34(38.2 \%)$ & $55(61.8 \%)$ & & $34(38.2 \%)$ & $55(61.8 \%)$ & \\
\hline $\begin{array}{l}25-28 \\
(n-154)\end{array}$ & $76(49.3 \%)$ & $78(50.9 \%)$ & & $55(35.7 \%)$ & $99(64.3 \%)$ & & $63(40.9 \%)$ & $91(59.1 \%)$ & \\
\hline $\begin{array}{l}29-33 \\
(n-85)\end{array}$ & $44(51.8 \%)$ & $41(48.2 \%)$ & & $33(38.8 \%)$ & $52(51.2 \%)$ & & $37(43.5 \%)$ & $48(56.5 \%)$ & \\
\hline
\end{tabular}

*Trend chi square test.

Table 6: Association of knowledge of obstetric danger signs and education among study participants.

\begin{tabular}{|c|c|c|c|c|c|c|c|c|}
\hline Variable & Antepartum & $\begin{array}{l}\text { P- } \\
\text { value }\end{array}$ & Labour & p-value & & Post partum & & $\begin{array}{l}\text { P- } \\
\text { value }\end{array}$ \\
\hline Illiterate (7) & $3(42.9 \%) \quad 4(57.1 \%)$ & \multirow{3}{*}{0.012} & $0(0 \%)$ & $7(100 \%)$ & \multirow{3}{*}{0.001} & $2(28.6 \%)$ & $5(71.4 \%)$ & \multirow{3}{*}{0.019} \\
\hline $\begin{array}{l}\text { Up to high } \\
\text { school (339) }\end{array}$ & $159\left(46.9 \% \begin{array}{l}180 \\
(53.1 \%)\end{array}\right.$ & & $119(35.1 \%)$ & $220(64.9 \%)$ & & $133(39.2 \%)$ & $206(60.8 \%)$ & \\
\hline $\begin{array}{l}\text { Graduate } \\
\text { and above } \\
\text { (8) }\end{array}$ & $8(100 \%) \quad 0(0 \%)$ & & $7(87.5 \%)$ & $1(12.5 \%)$ & & $7(87.5 \%)$ & $1(12.5 \%)$ & \\
\hline
\end{tabular}

*chi square test

Table 7: Association of knowledge of obstetric danger signs and socioeconomic status among study participants.

\begin{tabular}{|llllllll|}
\hline Variable & Antepartum & & p-value & Labour & & & p-valu Postpartum \\
value
\end{tabular}

*chi square test

Table 8: Association of knowledge of obstetric danger signs and antenatal visits among study participants.

\begin{tabular}{|c|c|c|c|c|c|c|c|c|c|}
\hline ANC visits & Antepartum & & P-value & Labour & & P-valut & Postpartum & & $\begin{array}{l}\text { P- } \\
\text { value }\end{array}$ \\
\hline 1 & $17(20 \%)$ & $68(80 \%)$ & \multirow{2}{*}{0.001} & $15(17.6 \%)$ & $70(82.4 \%)$ & \multirow{2}{*}{0.001} & $27(31.8 \%)$ & $58(68.2 \%)$ & \multirow{2}{*}{0.072} \\
\hline 2 and more & $153(56.9 \%)$ & $116(43.1 \%)$ & & $111(41.3 \%)$ & $158(58.7 \%)$ & & $115(42.8 \%)$ & $154(57.2 \%)$ & \\
\hline
\end{tabular}

Table 9: Association of Knowledge of obstetric danger signs and husband's education status among study participants.

\begin{tabular}{|c|c|c|c|c|c|c|c|c|c|}
\hline Variable & Antepartum & & P-value & Labour & p-value & & Post partum & & P-value \\
\hline $\begin{array}{l}\text { Illiterate } \\
(4)\end{array}$ & $2(50 \%)$ & $2(50 \%)$ & \multirow{3}{*}{0.830} & $0(0 \%)$ & $4(100 \%)$ & \multirow{3}{*}{0.010} & $0(0 \%)$ & $4(100 \%)$ & \multirow{3}{*}{0.171} \\
\hline $\begin{array}{l}\text { Up to high } \\
\text { school (312) }\end{array}$ & $148(47.4 \%)$ & $164(52.6 \%)$ & & $105(33.7 \%)$ & $207(66.3 \%)$ & & $124(39.7 \%)$ & $\begin{array}{l}188 \\
(60.3 \%)\end{array}$ & \\
\hline $\begin{array}{l}\text { Graduate anc } \\
\text { above }(38)\end{array}$ & $20(52.6 \%)$ & $18(47.4 \%)$ & & $21(55.3 \%)$ & $17(44.7 \%)$ & & $18(47.4 \%)$ & $\begin{array}{l}20 \\
(52.6 \%)\end{array}$ & \\
\hline
\end{tabular}

*chi square test 
Out of 142 study participants, $92(64.8 \%)$ participants had knowledge about heavy bleeding and 59 (41.5\%) had knowledge about painful urination as a danger sign during postpartum period while $33(23.2 \%)$ participants had the knowledge about smelly vaginal discharge as a danger sign during this period (Table 4).

Knowledge of obstetric danger signs increases with the age during all three periods and age group 29-33 years had more knowledge compare to other age groups but this trend was not statistically significant (Table 5).

Hundred percent, $87.5 \%$ and $87.5 \%$ of participants who were graduate and above had the knowledge of at least one danger sign during antenatal period, labour and postpartum period respectively. These associations were found statistically significant among all three periods (Table 6).

Participants who belongs to upper class (class I and class II), among them $56(64.4 \%), 39(44.8 \%)$ and $38(43.7 \%)$ had the knowledge of at least one danger sign during antenatal period, labour and postpartum period respectively most, compare to other socioeconomic class. This association was significant during antenatal period and postpartum period (Table 7).

Table 10: Association of knowledge of obstetric danger signs and antenatal parity among study participants.

\begin{tabular}{|c|c|c|c|c|c|c|c|c|c|}
\hline Parity & Antepartum & & P-value & Labour & p-value & & Post partum & & P-value \\
\hline $\begin{array}{l}\text { Primipa } \\
\text { ra (111) }\end{array}$ & $52(46.8 \%)$ & $59(53.2 \%)$ & \multirow{2}{*}{0.765} & $39(35.1 \%)$ & $72(64.9 \%)$ & \multirow{2}{*}{0.903} & $34(30.6 \%)$ & $77(69.4 \%)$ & \multirow{2}{*}{0.014} \\
\hline $\begin{array}{l}\text { Multipara } \\
(243)\end{array}$ & $118(48.6 \%)$ & $125(51.4 \%)$ & & 87 (35.9) & $156(64.2 \%)$ & & $108(44.4 \%)$ & $135(55.6 \%)$ & \\
\hline
\end{tabular}

Participants who had 2 and more antenatal visits had more knowledge of obstetric danger signs compare to who had one and less visit and this association was statistically significant during antenatal period and labour (Table 8).

Participants whose husband had education up to graduation and above had better knowledge of obstetric danger sign compare to others and it was statistically significant during labour (Table 9).

Participants who were multipara, had more knowledge of danger signs during all three periods compare to primipara and during postpartum period, it was found to be statistically significant (Table 10).

\section{DISCUSSION}

The present study was a descriptive, cross-sectional, hospital-based study conducted amongst pregnant female. The study aimed to find out the knowledge of obstetric danger signs along with the factors associated with it.

In present study $48 \%$ participants knew about atleast one danger sign during pregnancy and results are comparable to that reported by Haleema $\mathrm{M}$ et al, in Mangalore, Karnataka where it was found to be $54.7 \% .{ }^{13}$ Its lower when compared to study conducted by Sahithi KJ et al in Hyderabad Telangana and Agarwal S et al in Indore city, in which they found that $73.5 \%$ and $79.2 \%$ of the respondents knew at least one danger sign during pregnancy respectively. ${ }^{12,14}$ This difference in results can be attributed to the different criteria used for assessing knowledge. A study conducted by Acharya et al, also found that only $27.8 \%$ women knew any one danger sign during pregnancy, and Mukhopadhya et al, study also observed that proportion of women knowing at least one danger sign ranged from $12.1 \%$ to $37.2 \%$ and this difference can be due to different methods and settings. ${ }^{15,16}$

In present study $85.9 \%$ participants knew about abdominal pain as a major danger sign during pregnancy and similar results were found in the study conducted by Nithya et al, in which Severe abdominal pain $(n=232$; $60.7 \%$ ) was the most commonly known danger sign of pregnancy followed by heavy bleeding $(n=216 ; 56.5 \%)$ and contrary to this study, study conducted by Sahithi KJ et al in which about $39 \%$ of the study subjects mentioned vaginal bleeding as the key danger sign during pregnancy. ${ }^{12,17}$

In present study $35.6 \%$ participants had the knowledge of at least one danger sign during labour, which is lower compared to study conducted by Sahithi KJ et al and Agarwal S et al, Indore city, in which they found $67.5 \%$ and $78.5 \%$ participants had the knowledge of at least one danger sign during labour respectively. ${ }^{12,14}$ In present study $83.3 \%$ participants knew about heavy vaginal bleeding as a key danger sign during labour, others were vaginal tearing $(57.1 \%)$, and water break (47.6\%). Similar finding was found by Bhumi MA et al in which severe bleeding $(71.5 \%)$, retained placenta $(68.6 \%)$, edema hands/feet/face $(64.5 \%)$ and convulsions $(57.6 \%)$ were most commonly known. ${ }^{18}$ Current study revealed that $42.2 \%$ participants had the knowledge of at least one danger sign during postpartum period and $64.8 \%$ participants had knowledge about heavy bleeding, $41.5 \%$ and $23.2 \%$ participants had the knowledge about painful urination and smelly vaginal discharge respectively as a 
danger sign during this period. Study conducted by Bhumi MA et al revealed that severe bleeding per vagina (74.0\%), foul smelling discharge $(72.6 \%)$, and high fever $(68.6 \%)$ were key danger sign during post-natal period known by study participants. ${ }^{18}$ Present study revealed that educational status of mother, socioeconomic status of participants and ANC visits were showing statistically significant association with knowledge of obstetric danger signs. Similarly, Vijay et al, found in their study that educational status had significant association with level of knowledge on danger signs during pregnancy and study conducted by Bhumi MA et al, showed that there is a significant association between knowledge scores about danger signs with mother's age and education. ${ }^{17,19}$ In present study there was no significant association was found between religion, locality, age, parity and knowledge of obstetric danger signs.

\section{CONCLUSION}

The present study revealed that a significant number of mothers (less than 50\%) are still not knowledgeable about obstetric danger signs. Maternal educational level, husband educational level, ANC visits, family monthly income, and being multiparous, were factors found to be significantly associated with mothers' knowledge of obstetric danger signs.

Awareness of key obstetric danger signs need to be given focus as it makes women and their families ready for prompt and appropriate decisions and measures in case of obstetric danger signs among pregnant women. Health education dissemination strategies on obstetric danger signs need to be continuously done at the health facility and community levels.

\section{Funding: No funding sources}

Conflict of interest: None declared

Ethical approval: The study was approved by the Institutional Ethics Committee

\section{REFERENCES}

1. WHO Maternal Mortality Ratio, 2018. Available at: http://www.who.int/healthinfo/statistics/indmaternalmor tality/en.

2. UNICEF India Maternal health, 2018. Available at: http://unicef.in/Whatwedo/1/Maternal-Health.

3. Maternal Mortality, 2018. Available at: http:// www.who.int $>$ news $>$ fact sheets $>$ detail.

4. Thaddeus S, Maine D. Too far to walk: maternal mortality in context. Soc Sci Med. 1994;38(8):1091110 .

5. World Health Organization: Mother-Baby Package: Implementing safe motherhood in countries. Practical guide WHO/FHE/MSM/94.11. Geneva.
6. JHPIEGO. Monitoring birth preparedness and complication readiness: tools and Indicators for maternal and newborn health. Baltimore: 2004.

7. Starrs AM. Safe motherhood initiative: 20 years and counting. Lancet. 2006;368(9542):1130-2.

8. Koblinsky MA, Campbell O, Heichelheim J. Organizing delivery care: what works for safe motherhood? Bull World Health Organ. 1999;77(5):399-406.

9. Bell J, Hussein J, Jentsch B, Scotland G, Bullough C, Graham W. Improving skilled attendance at delivery: a preliminary report of the SAFE strategy development tool. Birth. 2003;30(4):227-34.

10. Paxton A, Maine D, Freedman L, Fry D, Lobis S. The evidence for emergency obstetric care. Int J Gynaecol Obstet. 2005;88(2):181-93.

11. Graham W, Themmen E, Bassane B, Meda N, De Brouwere V. Evaluating skilled care at delivery in Burkina Faso: principles and practice. Trop Med Int Health. 2008;13(1):6-1.

12. Sahithi K, Venkat C. Awareness of danger signs during pregnancy, labour, child birth and during the first seven days of life attending antenatal care. Int J Repro Contra Obste Gynecol. 2017;8:4106-10.

13. Haleema M, Raghuveer P, Kiran R, Mohammed IM, Mohammed IS, Mohammed M. Assessment of knowledge of obstetric danger signs among pregnant women attendinga teaching hospital. J Family Med Prim Care. 2019;8:1422-6.

14. Shankar A, Kaur R, Gnana J, Rasheed N. Making pregnancy safer - birth preparedness and complication readiness among antenatal women. Indian J Com Med. 2015;40(2):127-34.

15. Acharya AS, Kaur R, Prasuna JG, Rasheed N. Making pregnancy safer-birth preparedness and complication readiness study among antenatal women attendees of a primary health center, Delhi. Indian J Com Med. 2015;40:127-34.

16. Mukhopadhyay DK, Mukhopadhyay S, Bhattacharjee S, Nayak S, Biswas AK, Biswas AB. Status of birth preparedness and complication readiness in Uttar Dinajpur District, West Bengal. Indian J Public Health. 2013;57:147-53.

17. Nithya R, Dorairajan G, Chinnakali P. Do pregnant women know about danger signs of pregnancy and childbirth? Int J Adv Med Health Res. 2017;29:4(1):117.

18. Bhumi M, Chajhlana S. Knowledge of obstetric danger signs among pregnant women attending antenatal clinic at rural health training centre. Int J Com Med Public Health. 2018;6:2471-5.

19. Vijay N, Kumare B, Yerlekar D. Awareness of obstetric danger signs among pregnant women in tertiary care teaching hospital. JP Journals. 2015;7(3):171-5.

Cite this article as: Kumar A, Yadav G, Zutshi V, Bodat S. Knowledge about obstetric danger signs among pregnant women attending antenatal clinic in a tertiary care hospital of Delhi: a cross sectional study. Int J Reprod Contracept Obstet Gynecol 2019;8:3738-43. 